\title{
LOS ESTUDIOS SOBRE EL ESPAÑOL COLOQUIAL Y LA LINGÜÍSTICA*
}

\author{
ANTONIO NARBONA
}

Universidad de Sevilla

\section{RESUMEN}

Entre las aportaciones de los estudios sobre el español coloquial a la lingüística destacan la ampliación y más adecuada delimitación del objeto y la superación de los límites teóricos y metodológicos de los paradigmas funcional y formal. Abren, además, unas posibilidades de indagación en ámbitos que van desde la historia de la lengua a la lingüística aplicada. El examen de la técnica constructiva de los enunciados conversacionales facilita también la integración del componente pragmático en la descripción gramatical.

Palabras clave: español coloquial, sintaxis, análisis del discurso, pragmática, oralidad y escritura.

\section{ABSTRACT}

The extension and more adequate delimitation of the linguistic object and the superseding of the theoretical and methodological limits of the functional and formal paradigms stand out among the contributions of the studies of colloquial Spanish to linguistics. In addition, new opportunities to investigate in different fields such as history of the language or applied linguistics are opened. The in-depth study of the constructive technique of the conversational statements enables as well the integration of the pragmatic component in the grammatical description.

Key Words: colloquial Spanish, syntax, discourse analysis, pragmatics, orality and writing.

0 . No facilita el estudio del español coloquial el que todo el mundo crea saber lo que significa «hablar coloquialmente», decir algo «en términos coloquiales» o en «tono coloquial», etc., expresiones que no solo se utilizan habitualmente como escudo protector frente a reales o

\footnotetext{
* Ponencia presentada en el XLI Simposio Internacional de la Sociedad Española de Lingüística (Universitat de València, del 31 de enero al 3 de febrero de 2012).
} 
posibles críticas, sino que incluso sirven para defenderse jurídicamente ante una acusación formal de injuria ${ }^{1}$. ¿Qué es el español coloquial? La pregunta me fue planteada por Antonio Briz para iniciar el debate en una mesa redonda durante el V Congreso Internacional de Historia de la Lengua Española, celebrado en la Universidad de Valencia, en el año 2000. Tras unos segundos de silencio, repliqué "¿Y tú me lo preguntas?», lo que provocó un momentáneo desconcierto. Al evocar la conocidísima Rima XXI de Gustavo Adolfo Bécquer ( ¿Qué es poesía?, dices mientras clavas / en mi pupila tu pupila azul. / ¿Qué es poesía? ¿Y tú me lo preguntas? / Poesía... eres tú»), no era mi intención, claro es, escurrir el bulto ni, mucho menos, devolver la pelota al moderador. Simplemente quería poner de manifiesto que ni siquiera es fácil separar lo coloquial de lo literario, en apariencia lo más distante. Y pese a que no cesan los intentos ${ }^{2}$, seguimos sin una respuesta satisfactoria.

En realidad, siempre que con un adjetivo se pretende acotar una variedad del español (o de cualquier otra lengua histórica), no debe perderse de vista que se captan «solo aspectos parciales del evento comunicativo» al que pretende aplicarse (Oesterreicher 2005, p. 733). Si cuantos más usuarios se sirvan de una modalidad de uso, más precauciones han de tomarse, toda cautela será poca en el caso de la coloquial, el tipo de interacción comunicativa por antonomasia», aunque, claro es, no todos, ni mucho menos, hablamos coloquialmente de igual modo. En realidad, la expresión «lengua coloquial» no debería emplearse en singular.

Doy por supuesto, lo que quizás sea mucho suponer, que es compartida la idea de que la más clara aportación a la lingüística se sitúa en la «macrosintaxis», es decir, la técnica constructiva libre del discurso, cuyo análisis ha de llevarse a cabo desde una perspectiva "pragmática». Por haberse centrado preferentemente en la pronunciación y en el léxico, entre otras razones, ni la Dialectología, pionera en la atención al habla viva, ni la Sociolingüística pueden considerarse propiamente sus precedentes ${ }^{3}$.

\footnotetext{
${ }^{1}$ Como si nada serio o en serio pudiera decirse coloquialmente. En una de las causas en que el conocido locutor F. Jiménez Losantos tuvo que acudir a los tribunales como imputado, se defendió diciendo que se había limitado a hacer «comentarios en tono coloquial» sobre los atentados del 11 de marzo de 2004.

${ }^{2}$ Cf. Luis Cortés 2002b. Hace un minucioso análisis de las razones de la vacilación terminológica y de la indefinición del término «español coloquial» Araceli López Serena 2007b.

${ }^{3}$ Fuera del quehacer de los lingüistas, como es fácil suponer, la sintaxis pasa casi inadvertida. Una obra que a punto estuvo de obtener un prestigioso premio literario por - a juicio del jurado- su fidelidad al lenguaje «popular», Historias del Kronen, de José Ángel Mañas (posteriormente llevada al cine con gran éxito), arranca así: «Me jode ir al Kronen los sábados por la tarde porque está siempre hasta el culo de gente. No hay ni una puta mesa libre y hace un calor insoportable. Manolo, que está currando en la barra, suda como un cerdo. Tiene las pupilas dilatadas y nos da la mano al vernos». Bastaría eliminar el término puta y sustituir las
} 
Aunque voy a limitarme a los estudios sobre el español llevados a cabo en España, no creo que los realizados fuera de nuestro país obliguen a modificar sustancialmente estas consideraciones.

Hace casi treinta años, en el Simposio que esta SEL celebró en Córdoba, presenté una ponencia titulada «Problemas de sintaxis coloquial andaluza» (Narbona 1986). Con el adjetivo andaluza no pretendía otra cosa que achicar algo un terreno, el de lo «coloquial», que me desbordaba -y me sigue desbordando- por su amplitud. El sustantivo problemas (y el adjetivo problemática) ha seguido siendo término muy empleado en los títulos de mis trabajos. Bastantes de esos problemas tienen que ver con la escasez de estudios, otros con el poco rigor de buena parte de los existentes.

Algo después, sin que pueda precisar con exactitud cuándo, pasé unos días en Valencia, con un grupo de jóvenes que, capitaneados por A. Briz, y todavía sin bautizar como Val.Es.Co, estaban decididos a dedicar tiempo y esfuerzos a intentar llenar algunas de esas carencias y superar las debilidades teóricas y metodológicas. No hace falta decir que sus logros han superado con mucho las expectativas y previsiones de entonces. Todos ellos, que siguen siendo jóvenes, han tenido una brillante carrera académica y profesional, y la referencia al Grupo resulta hoy obligada no solo cuando del español coloquial se trata.

Luis Cortés, que se encontraba algo «perdido» por tierras leonesas, vino a Córdoba (tampoco recuerdo bien si antes o después de esa estancia en Valencia), para hablarme de su interés por lo coloquial, reflejado ya en su Tesis Doctoral (un resumen apareció en 1982 con el título Segmentación y caracterización sintácticas. Ensayo de un método sociolingüistico, y posteriormente, en 1986, se publicó íntegra como Sintaxis del coloquio. Aproximación sociolingüistica, en ambos casos por la Universidad de Salamanca), dirigida, por cierto, por A. Llorente, que bastantes años antes, en la Universidad de Granada, también había sido director de mi Memoria de Licenciatura El habla de Olivares (Sevilla): Notas para una sintaxis dialectal, 1971. De la labor de Luis Cortés, que, además de haber puesto en marcha Oralia, publicación periódica ya consolidada, ha ido y sigue recopilando y ordenando cuanto puede ser de utilidad en este campo, tampoco es preciso decir mucho.

El interés por el español coloquial no ha dejado de acrecentarse, y a un ritmo poco usual en lingüística, disciplina en la que los verdaderos avances se producen muy lentamente y en espiral, de modo que la curva apenas suele distanciarse del punto por el que había pasado en su trazado anterior. El número de publicaciones es ya inabarcable; se ha

expresiones jode (por molesta), hasta el culo (por lleno), currando (por trabajando) y como un cerdo (por sin parar) para comprobar que nada hay en la sintaxis (absolutamente canónica) de tal estilo «popular». 
celebrado un buen número de reuniones científicas específicas; en muchas de nuestras Universidades «español coloquial» es una materia que forma parte de los planes de estudios (en la que se inscribe la mayoría de los alumnos del programa Erasmus que vienen a cursar Filología), etc. Pero no es mi intención hacer un balance de lo hasta aquí realizado, tarea de la que, como acabo de decir, se encarga Luis Cortés, quien también ha esbozado su personal status quaestionis en un trabajo incluido en el número monográfico de Español Actual. Revista de Español Vivo correspondiente a 2002, coordinado por A. M. ${ }^{-}$Vigara, que, por cierto, en su escrito de presentación («Estudio del español coloquial: razones para el optimismo») arranca así: «No comparto (en absoluto) la visión extremadamente pesimista, mantenida desde hace muchos años -desde siempre, en realidad, si seguimos lo manifestado en sus publicaciones- hasta hoy, por el profesor Antonio Narbona» (p. 6). Y recurre a un extenso y manipulador comentario de unas frases de uno solo de mis trabajos, comentario tan alambicado, que incluso se siente obligada a pedir disculpas a los lectores, consciente de que los está sometiendo -dice en una nota- a un «esfuerzo descodificador extra» [ sic].

Nada más lejos de la verdad. Solo desde la ignorancia podría yo dejar de reconocer el gran salto cualitativo que ha supuesto lo conseguido en los últimos decenios por investigadores que a menudo han tenido que trabajar como auténticos francotiradores. Creo que toda actitud crítica que haga aflorar los problemas debe calificarse de «optimista», no, claro es, en la primera acepción del DRAE («propensión a juzgar las cosas en su aspecto más favorable»), sino en la segunda («pretensión de mejorarlas y, en la medida de lo posible, perfeccionarlas»), sin duda menos ingenua. No minusvaloro la predisposición al apasionamiento, pero si no es frenada racionalmente, puede acabar por enturbiar el cabal conocimiento de la realidad. Y prueba de que no cunde en mí el desánimo es que, aquí me tienen, cuarenta años más tarde, volviendo a la carga, con no menos entusiasmo, pero procurando seguir sin perder la cabeza.

$\mathrm{Al}$ margen de actitudes optimistas o pesimistas, que en el quehacer científico a ningún sitio conducen, de lo que ese creciente interés por las modalidades coloquiales ha podido aportar a los estudios lingüísticos, importa destacar especialmente cuanto ha servido de foco de renovación para la delimitación del objeto y la clarificación de la metodología para abordarlo, uno y otra indesligables.

1. ¿En qué medida ha contribuido a deslindar y definir mejor aquello de lo que los lingüistas han de ocuparse? Habría que empezar -primer problema - por las fuentes de las que se extraen los datos, asunto nada baladí en lingüística, pues de ello dependerá que las explicaciones estén o no bien encaminadas. Por supuesto, la relación entre las teorías y los 
datos a que han de aplicarse no es algo que afecte exclusivamente a la investigación sobre el español coloquial. Siempre ha preocupado a los lingüistas (Narbona 2003a), sobre todo desde que F. de Saussure nos hizo ver que, a diferencia de lo que sucede en las ciencias que «opèrent sur des objets donnés d'avance et qu'on peut considérer ensuite à differents points de vue», en la lingüística «c'est le point de vue qui crée l'objet» (1985, p. 23). Aunque para algunos «es la teoría la que determina el valor de los datos y no los datos los que señalan el valor de la teoría» (Anula 2000, p. 21), muchos piensan que son las descripciones y explicaciones las que se hallan mediatizadas por los datos de que se parta, unos datos que (seleccionados por razones o preferencias distintas en cada caso) necesariamente han de provenir de las muy variadas actuaciones de los no menos diversos tipos de usuarios. Prueba de que estamos ante algo no resuelto es que, por ejemplo, I. Bosque y V. Demonte, directores de la Gramática descriptiva de la lengua española, 1999, pese a confesarse partidarios de la «introspección» (por permitir «usar datos negativos, es decir, secuencias agramaticales cuya inexistencia muestra alguna pauta consistente en el sistema gramatical»), se abstuvieron de dar a los colaboradores instrucción alguna «sobre las fuentes de datos que debían manejar», limitándose a instarlos «a hacer uso del mayor número posible de ellas» (p. XXIX) ${ }^{4}$. Se trata de una relación, cuya historia, cuando se haga (la de las teorías ha sido reiteradamente trazada, pero no la de los datos), puede resultar «tumultueuse et changeante», y en la que una etapa «particulièrement intéressante et révélatrice» será la marcada por la incorporación «des données orales», desatendidos (especialmente por los gramáticos) por la «réaction de rejet et de méfiance quelles ont longtemps suscitée» (Willems 1998, p. 80).

Pero ¿qué hay que entender por datos orales? La oralidad y la escritura (o escritur [al] idad) no se definen únicamente por el canal empleado

\footnotetext{
${ }^{4}$ Recomendación que no todos, ni mucho menos, han seguido. Hay «desobediencias» llamativas: en el capítulo 64 (Las funciones informativas: Tema y foco), María Luisa Zubizarreta se ha servido exclusivamente de ejemplos inventados. Sobra decir que en el análisis de la sintaxis coloquial, cuanto menos se recurra a la introspección, mejor. El segundo objetivo de la Nueva gramática de la lengua española, 2009, de la RAE y de la Asociación de Academias de la Lengua Española (el primero sigue siendo «describir las construcciones gramaticales propias del español general, así como reflejar adecuadamente las variantes fónicas, morfológicas y sintácticas que una determinada comunidad puede considerar propias de la lengua culta, aun cuando no coincidan enteramente con las opciones favorecidas en otras áreas geográficas»), es «registrar aquellas variantes conversacionales de la lengua no estándar atestiguadas en el mundo hispánico, siempre que estén bien documentadas y tengan interés para la descripción de las estructuras morfológicas y sintácticas». ¿Se ha cumplido, siquiera sea con esas estrictas condiciones? En muy pequeña medida. Aunque ha acabado con el casi monopolio de la literatura como fuente de los datos, no abundan los ejemplos «de procedencia oral». Ello no debe extrañar en una obra que es más «descriptiva» que «normativa» y que reconoce que «la norma tiene hoy carácter policéntrico», por lo que, pese a las intenciones, ha de admitir que «no es posible presentar el español de un país o de una comunidad como modelo panhispánico».
} 
(fónico-auditivo y gráfico, respectivamente), sino también, y sobre todo, por el grado en que sobre el uso inciden parámetros muy diversos que reflejan la inmediatez (o proximidad) o la distancia comunicativa entre los participantes en cada tipo de acto de comunicación (Koch y Oesterreicher 2000); es decir, por la mayor, menor o nula connivencia o complicidad entre ellos, lo que influirá decisivamente en su elección (cuando y en la medida en que les es posible elegir) de la variedad más adecuada. Todas las modalidades, orales o escritas, deben contemplarse, pues, dentro de una misma y única escala, algo que suele perderse de vista cuando la atención se centra exclusivamente en uno de sus extremos, especialmente en el que se supone más difícilmente sistematizable.

No hace falta señalar las consecuencias que de esto derivan, y no únicamente en la lingüística sincrónica. Si solo se consideraran orales los usos medialmente hablados, es obvio que no dispondríamos de testimonios fehacientes de los mismos más que desde que se ha podido contar con técnicas y procedimientos para su registro y fijación, es decir, cuando, bien avanzado el siglo xx, empezó a dejar de ser cierto eso de que «las palabras se las lleva el viento». En tal caso, más que de rejet o de méfiance hacia los datos orales, habría que hablar simplemente de la imposibilidad de contar con ellos. Nadie ha defendido, sin embargo, que no se pueda conocer nada de la oralidad hasta ese momento. Al contrario, la investigación de lo oral a partir de lo escrito para el largo periodo en que solo disponemos de textos es, se ha dicho, la tarea más fascinante que ante sí tienen los estudiosos de la historia de las lenguas. Habría que añadir que resulta tan problemática como seductora. Aunque no puedo detenerme en esto, de lo que me he ocupado en otro lugar (Narbona 2012), interesa recordar que la utilización no discriminada de las fuentes escritas ha conducido a interpretar de modos distintos e incluso contrarios la evolución de un mismo fenómeno. Si bien pocos dudan de que en el habla se encuentra el motor de la mayoría de los cambios lingüísticos, como resulta imposible comprobar su desarrollo hasta fecha muy reciente, y, en general, es improcedente proyectar, sin más, la situación presente sobre el pasado, no extraña que al carácter oral (a menudo se piensa en el coloquial) se atribuyan, en unos casos, la extensión y vitalidad de una construcción, y, en otros, su decadencia. Así, según Lola Pons 2007, el que no prosperara como procedimiento cohesivo la construcción relativa con antecedente adjunto ( «E oyó misa el Rey, e ellos aparte, la qual misa dio el obispo de León») se debió a que era un recurso «más orientado a la distancia que a la inmediatez comunicativa». En cambio, la «corta vida»-desde mediados del siglo XVII a mediados del xx-de conque consecutivo, de "estatuto categorial problemático», se ha achacado «a su temprana conexión con la lengua hablada» (Girón 2003a, 
2003b, 2004) $)^{5}$. Aparte de que no está claro que haya decaído su empleo, especialmente en la lengua popular (Me duele a mí / conque ya me figuro lo que estás pasando tú $)^{6}$, en la que incluso se integra en ciertos moldes sintácticos más o menos fijados, como es con el padre encima / y no estudia // conque / solo / menos (Cortés Parazuelos 1994) ${ }^{7}$, es discutible que ello hubiera sido propiciado por su reclusión en el habla. Ni la abundancia ni la escasez de testimonios de un fenómeno garantizan su carácter más o menos oral, por lo que solo la utilización diferenciada de los tipos de textos y discursos a la luz de las relaciones recíprocas entre lo oral y lo escrito ha permitido entender, por ejemplo, el progreso de pues como marcador discursivo (Iglesias 2000a) y el avance de que causal a costa de $c a$ (Iglesias 2000b). A pesar de que el minucioso rastreo que está llevando a cabo en textos literarios y no literarios el mismo Girón (2009, 2012) inclina a pensar que hasta bien entrado el siglo pasado no empezó a ser dominante el que (el bolígrafo con el que escribo), frente al relativo sin artículo (el bolígrafo con que escribo), sigue sin estar del todo claro que solo entonces se invirtieran los términos y pasara la primera fórmula a ser la «no marcada» ${ }^{8}$. Una construcción como la de «participio absoluto» o «absoluta de participio» (Terminada la conferencia, se servirá una copa en la cafetería), pese a estar ampliamente documentada en todas las épocas, nunca ha debido de ser usual en las actuaciones propias de la inmediatez comunicativa (Narbona 1996a) ${ }^{9}$. Hay, sin em-

${ }^{5}$ Aduce también otras causas, como «su temprana especialización en introducir enunciados directivos y amenazantes de la imagen del interlocutor» y el hecho de que «su aparición no supone la innovación de un esquema oracional más gramaticalizado que el de origen» (Girón 2004, p. 184).

${ }^{6}$ En un trabajo de 1978, recogido en R. Lapesa 2000, p. 910, afirmaba que se emplea «en todos los estratos». Y en la Nueva gramática académica (2009) solo se dice que «es menos usada en la lengua literaria que en la prosa ensayística o en la lengua coloquial» (p. 3519).

7 En general, los conectores «concesivos», o que expresan algún tipo de «contraposición», pasan más fácilmente a la escritura que los «consecutivos», que de un modo u otro implican una deducción lógica, y aunque no es raro el desplazamiento significativo de algunos de los segundos -como asi que o de modo que, además de con que- hacia un sentido meramente contrastivo, sí lo es el movimiento inverso. Cada vez más y en más diversas clases de textos se encuentran y eso que o con todo y con eso, en los que no es casual la presencia del «neutro» desindividualizador eso. He aquí el titular de portada del número del diario gratuito $20 \mathrm{Mi}$ nutos correspondiente a la edición sevillana del 11 de octubre de 2007: «El bonobús sube un $15 \%$, el agua el $5 \%$... y eso que prometieron congelarlos». En otros giros, también con términos "neutros", como lo cual que y lo que es que, hoy vivos, al menos en el habla de ciertas regiones, se descubre igualmente cierto valor adversativo o contrastivo (Narbona 1986).

${ }^{8}$ Alude también Girón a otros factores que influyen en ese lento avance de el que, como el triunfo de ya sabes a lo que vengo sobre ya sabes lo a que vengo, o el que no sobrepasen el siglo XVII construcciones como olvidar la cuyo so o no son días de fe los en que vivimos, de las que ya se ocupó Lapesa 1966.

${ }_{9}$ De no ser así, mal se explicaría que, por ejemplo, en El Patrañuelo (1567), de Juan de Timoneda, que algunos tienen por la más importante colección de cuentos antes de las Novelas ejemplares cervantinas, pese a aparecer constantemente y con toda clase de verbos (solo en la 
bargo, quien piensa lo contrario, es decir, que se trata de un esquema «especialmente adecuado para una sintaxis suelta», que muestra «la presencia de la oralidad en textos escritos» (Elvira 2005). Difícilmente pueden encontrarse en español medieval manifestaciones escritas en que se atestigüe el empleo del artículo en casos como ; cuidado con el escalón!, que Company 2006 achaca a su pertenencia a «la lengua oral». El que no haya constancia hasta mediados del siglo pasado (también por ser uso propio del «registro oral coloquial») de la utilización de encima (de que) como marcador con valor contraargumentativo y refutativo ( $T u$ hijo es simpático, agradable, buena gente y, encima, te quejas. No te entiendo) no ha impedido a Garachana 2008, quien no duda en recurrir a las detectables modulaciones prosódicas ${ }^{10}$, aclarar parcialmente la historia de la expresión, que sitúa «en los límites de la gramaticalización». Los ejemplos pueden multiplicarse con facilidad.

Estas incursiones en el pasado muestran que distinguir "grados de oralidad» (o de «escritura») es tarea extraordinariamente compleja, y que no puede hacerse al margen de una diferenciación de los «géneros discursivos» y de las tradiciones en que se hayan cultivado en cada lengua y en cada fase de su historia. La conversación coloquial prototípica, aun perteneciendo a la más larga tradición (en realidad, tan antigua como la humanidad), no parece corresponder a un género discursivo homologable a los demás, lo que complica mucho su análisis, sobre todo si, como he dicho, se pretende hacer aisladamente.

La idea de que toda explicación lingüística ha de ser inicialmente histórica empieza a instalarse en los estudios de sintaxis coloquial. El trabajo de Pons Bordería 2008 acerca de esto es (Antes se trataba de persuadir, esto es, de conducir al interlocutor por una senda didáctica), incluido en un volumen editado por Kabatek 2008, puede servir de ejemplo ilustrativo. No se limita a trazar la trayectoria de tal expresión, cuyo origen sitúa en la traducción del latín id est en textos jurídicos, sino que trata de dar cuenta de su vitalidad, distinta de la de otros conectores de significado afín, como a saber, es decir y o sea.

La búsqueda de huellas o vestigios de la oralidad en la escritura del pasado puede ayudar no poco, como se ve, a aproximarse a la tan ansiada como inalcanzable historia global del español.

Es sabido que la preocupación por describir las actuaciones habladas arrancó, por fuerza, vinculada a, y mediatizada por, la escritura. La

Patraña VI encuentro ido el mercader, vueltos en el talegón, venido a noticia del tiratierra, venido delante del alcalde, vista la presente, oída la queja, medio turbado de lo que le había acontecido, oídas las partes, etc., además de abundantes gerundios también absolutos), no aparezca ningún caso en las intervenciones dialogadas (Narbona 2008b).

${ }^{10}$ Ya Alonso 1922 se percató de que solo recurriendo a la restitución del adecuado contorno melódico se podía comprender el sentido de como que y de cómo que, que aparecen ya en textos medievales. Cf. Narbona 1996b. 
grammaire des fautes, de Henri Frei 1929, tomó como base cartas de prisioneros de la primera Guerra Mundial. Y en la obra inaugural para el español, Spanische Umgangssprache, publicada ese mismo año, Werner Beinhauer, que no pretendía centrarse tanto en las faltas, errores o incorrecciones $^{11}$, como en las singularidades -anómalas o no-, se sirvió de textos teatrales (de los hermanos Álvarez Quintero, Arniches, Vital Aza, P. Muñoz Seca, etc.) en que creyó encontrar ese español «extraordinariamente expresivo, ingenioso e inagotablemente rico» que le interesaba ${ }^{12}$.

Y si bien la observación directa, facilitada por los modernos medios de grabación, llegó a hacer creer que es el mejor -incluso el único- camino para «enfrentarse con el habla viva, recogida en condiciones de garantía, esto es, sin que su autenticidad se vea perturbada», la tarea más «importante» (eso sí, «enteramente por hacer») de la lingüística (Criado de Val 1959, p. 211), lo cierto es que no solo no se ha prescindido, ni mucho menos, de las fuentes escritas, sino que a ellas se ha seguido recurriendo para investigar las modalidades orales, en general, y, en particular, las prototípicamente coloquiales, las más alejadas, en principio, de la escritura en la escala gradual a que antes me he referido $^{13}$. Y, lejos de disminuir, la explotación de ciertos textos, adecuadamente reorientada, se ha intensificado, lo que, como se verá, no deja de proporcionar ventajas. Al menos en esta línea de investigación, conocida como «escritura de lo oral», "mimesis del habla» u «oralidad simulada (o fingida)»-sobre la que volveré al final-, mi visión no puede ser más optimista.

11 En realidad, H. Frei advierte al lector de que no debe sorprenderse de la pretensión de hacer "gramática» de lo que suele considerarse su negación, pues muchas de las «faltas» no son tales y, desde luego, no son debidas al azar o a la negligencia.

12 El desarrollo de los estudios sobre una y otra lengua no ha transcurrido, sin embargo, de forma paralela. Mientras que en la búsqueda de la especificidad del français parlé pronto se sintió la necesidad de contar con instrumentos conceptuales y metodológicos nuevos, en España los análisis siguieron durante bastante tiempo anclados en un modo de proceder no muy distante del de W. Beinhauer, deudor, a su vez, de L. Spitzer, cuya obra Lingua italiana del dialogo había aparecido en 1922. Prueba de ello es la publicación en 2005 de una segunda edición -sin apenas modificaciones respecto de la primera de 1992- de la Morfosintaxis del español coloquial, un esbozo estilístico en el que, pese a que los ejemplos ya no son, en su mayoría, extraídos de textos, sino directamente tomados al oído (casi todos en la capital madrileña), la autora, Ana M. - Vigara, se atiene a la estructura del libro pionero del estudioso alemán.

13 La antología de Textos para el estudio del español coloquial, de F. González Ollé, que no ha dejado de reimprimirse desde su aparición en 1968, y en la que se acogen, además de algunas de las utilizadas por W. Beinhauer, otras obras teatrales (de autores que van desde J. Benavente a A. Diosdado, pasando por J. M. ํ Pemán, J. Calvo Sotelo, V. Ruiz Iriarte, M. Mihura, A. Buero Vallejo, A. Paso) y se agregan textos narrativos (de P. Baroja, A. Díaz-Cañabate, A. Zamora Vicente, C. J. Cela, F. García Pavón, M. Delibes, D. Medio, I. Aldecoa, R. Sánchez Ferlosio, C. Martín Gaite, etc.), sin que en la selección se advierta un criterio único ni homogéneo, fue pensada más bien, pese al título, para la enseñanza del idioma, especialmente a no hispanohablantes. 
Por lo que respecta al español coloquial actual, aunque falte mucho por hacer, disponemos ya de grabaciones y corpus orales transcritos suficientes para que muchos equipos puedan trabajar durante décadas. Pero no todos los investigadores terminan de liberarse de la creencia de que están ante un objeto específico que ha de contemplarse como distinto de aquel en que los lingüistas se han venido centrando, como si ante otra lingüística se encontraran, en lugar de limitarse a ensanchar el horizonte del mismo objeto de estudio.

2. Digamos algo de los métodos, no separables, como he dicho, de los datos observados. Para conocer en qué medida los modos de proceder en el examen del español coloquial han contribuido, o pueden hacerlo, a afinar los modelos de explicación lingüística, sería necesaria una previa labor de criba y filtro, de modo que fueran quedando a flote solo aquellos esfuerzos que hayan supuesto un claro paso adelante.

De los estudios de la lengua coloquial se esperaba mucho, quizás demasiado, y en un plazo breve. ¿Por qué no acaban de contribuir de manera decisiva a desbloquear metodológicamente la lingüística estructural, funcional o formal, para algunos bloqueada y al borde de la asfixia? Entre otras razones, porque mientras no se imponga realmente y, sobre todo, se plasme en la práctica la convicción de que lo verdaderamente relevante es la construcción del discurso, apenas se podrá avanzar en el entendimiento de las peculiaridades del habla y, por tanto, ayudar a renovar los métodos de explicación de los hechos lingüísticos. Tal convencimiento obliga, por un lado, a reformular muchas de las nociones básicas, empezando por las de «sistema», «norma», «competencia (idiomática y comunicativa)», etc., y, por otro, a replantearse buena parte de los conceptos con que, explícitamente o no, se ha venido operando, incluidas las unidades mismas.

Dado que el grupo Val.Es.Co, sobreponiéndose a la casi inexistencia de una teoría en que apoyarse, está empeñado desde hace unos años en la tarea de delimitar «un sistema de unidades para el estudio del lenguaje coloquial» ${ }^{14}$, no me detendré en lo que, con razón, se ve como un «terreno movedizo» (Cortés Rodríguez y Camacho 2005, p. 35) ${ }^{15}$. Me limitaré a insistir en ideas ya conocidas:

\footnotetext{
${ }_{14}$ Pese a que el trabajo así titulado (2003) -esbozado en otros anteriores- es calificado por el propio Grupo como «la primera presentación de conjunto que se puede considerar -valga la paradoja- provisionalmente definitiva», varios miembros de Val.Es.Co han vuelto sobre el asunto en diversas ocasiones. Cf. especialmente A. Briz 2011, A. Hidalgo 2011 y la comunicación presentada en este mismo Simposio por Adrián Cabedo y Elena López Navarro.

${ }^{15}$ No sorprende que los términos que se proponen para designar las unidades básicas del Análisis del discurso sean calificados pronto de ambiguos. Es lo que ha ocurrido, por ejemplo, con secuencia, puesto en circulación por la lingüística francesa (Adam, Roulet y colaboradores). Cf. Fuentes 2000.
} 
a) en la oralidad propia de la inmediatez comunicativa, en que lo enunciado se manifiesta como un flujo continuo, ni la oración ni sus constituyentes pueden tomarse como unidades operativas básicas, aunque no se cuente todavía con otras de «recambio» que resulten indiscutibles;

b) no se trata de buscar unidades sustitutivas que la «desbanquen», sino de abandonar la visión jerárquica de las unidades oracionales y las discursivas (ni unas ni otras, especialmente las segundas, bien definidas);

c) en esa búsqueda no hay que tratar de ajustar o acomodar los resultados de la producción enunciativa entre los interlocutores a unos esquemas sintácticos que fueron establecidos sin contar con esa «elaboración sintáctica $a$ dos (o más) voces» ${ }^{16} ; \mathrm{y}$

d) cualquiera que sea el coste teórico que ello pueda suponer, toda segmentación o división de ese fluir discursivo ha de contar con el componente prosódico, sin lo cual es imposible reconocer el papel que desempeñan la «combinación» y la «composición» de las unidades y la "posición» de sus partes integrantes en la cadena enunciativa, un papel que, además, tiene que ser descrito por el contenido que transmiten, más o menos informativo, pero rara vez coincidente con el meramente proposicional.

Es significativo que se haya llegado a sostener que la unidad central (noyau) en la organización de la lengua hablada es la «dotée d'une autonomie intonative et sémantique» (por ese orden), pues «l'analyse de l'intonation rend compte en partie des effets de regroupements que la syntaxe ne prend pas en charge» (Blanche-Benveniste 1998, pp. 112-113). Por ahí parecen caminar los miembros del Grupo valenciano, y los esfuerzos empiezan a dar resultados, como lo ponen de manifiesto los trabajos de A. Hidalgo y de sus discípulos (Cabedo Nebot 2009) ${ }^{17}$.

En la breve historia de los estudios sobre el español coloquial, bien conocida (Narbona 1997a, 1997b y 2004; Cortés Rodríguez 2002a), se puede advertir que la sintaxis (casi siempre microsintaxis) ha ido pasando de no (o apenas) estar presente en ellos a aspirar a convertirse en

\footnotetext{
${ }^{16}$ Las llamadas coconstrucciones, a que ello da lugar, siguen contemplándose como casos especiales de las unidades sintácticas comúnmente reconocidas. Así, en el intercambio - HACER YO / pero si ellos te dicen que tiene que ser asi -Es así, Montolío 2011, p. 315, interpreta que el primer hablante «inicia una oración condicional de la que enuncia solo la primera parte, la cláusula subordinada, y es su interlocutor quien la completa con la apódosis correspondiente». Cf. Narbona en prensa.

${ }^{17}$ Casi simultáneamente han aparecido el número 14 (2011) de ORALIA, con una extensa sección temática sobre «la interfaz entonación-discurso oral en el ámbito hispánico», coordinada por A. Hidalgo, y la obra, también editada por A. Hidalgo, junto con Y. Congosto y M. Quilis 2011, El estudio de la prosodia en España en el siglo XXI: perspectivas y ámbitos.
} 
la clave o centro. Lo que ha ocurrido es que antes de que tal pretensión se hiciera realidad, fue siendo subsumida por el análisis del discurso, que no puede adoptar otra óptica que la pragmática, vía de aproximación a la comunicación verbal que hoy todo lo engulle. He empleado el verbo engullir, porque, pese a no tener un objeto bien delimitado y no contar aún con planteamientos teórico-metodológicos perfilados, se está tragando buena parte del quehacer de los lingüistas, y no siempre con una masticación reposada y una buena digestión. Lo pragmático lo cubre todo, y el término figura ya en las reuniones (Pragmática del español hablado: Nuevas perspectivas para el estudio del español coloquial fue el título escogido para la celebrada aquí en Valencia en noviembre de 2009) y en las portadas de libros que tratan del español coloquial: El español coloquial en la conversación. Esbozo de pragmagramática (Briz 1998); La intensificación como categoría pragmática: revisión y propuesta (Albelda 2007) ${ }^{18}$; Español coloquial. Pragmática de lo cotidiano (Gaviño 2008) ${ }^{19}$; etcétera.

3. Muchos de los obstáculos con que se tropieza en el estudio de la sintaxis coloquial tienen que ver, en efecto, con el fuerte anclaje de la conversación en la situación en que se produce y con la explotación de mecanismos y recursos contextualizadores específicos. Entre ellos, como acabo de señalar, los prosódicos (que, en rigor, ni siquiera pueden ser transcritos $\left.{ }^{20}\right)$, decisivos para la interpretación del sentido ${ }^{21}$. En realidad,

\footnotetext{
${ }_{18}$ En el breve Prólogo a esta obra -derivada de la Tesis Doctoral de su autora-, que se ocupa de una «categoría pragmática», A. Briz la inserta en el «análisis pragmático de la conversación», y la califica de «estudio pragmalingüístico» que trata de «valores pragmáticos» y de «estrategias pragmáticas», sin que falte un «guiño a la sociopragmática», por lo que constituye una contribución al «desarrollo de la pragmática española». Cf. también Briz 2011. Y es que cuando nos situamos en la dimensión discursiva no cabe otra orientación que la pragmática, cuyo «reino» es, como se ha dicho, la conversación coloquial.

${ }_{19}$ Sus primeras palabras podrían servir, por cierto, de fácil y cómodo apoyo al ingenuo optimismo de algunos: «Los estudios sobre español coloquial están -podemos por fin decirloviviendo su punto más álgido $($ sic $)$ ».

${ }^{20}$ En los sistemas de transcripción se ha ido afinando bastante (Briz y Val.Es.Co 2002, Gómez Molina 2007, Moreno 2007, Vida Castro 2007, Moya 2007 y 2008, Ávila, Lasarte y Villena 2008, Lasarte, Sánchez, Ávila y Villena 2009, etc.), aunque el hecho mismo de que en algunos casos se prefiera ofrecer más de una propuesta (en el corpus coordinado por Moya 2008, la respuesta de una funcionaria con estudios medios a la pregunta ¿̨en qué consiste tu trabajo?, «transliterada» sin etiquetado soy lo que/ aho- ahora nos han cambiado el nombre/ antes éramos auxiliares de justicia, se etiqueta, "para su mejor comprensión», del siguiente modo: soy lo que/ aho <palabra cortada/ $>$ ahora nos han cambia $<[d]>0$ el nombre/ antes éramos <término $>$ auxiliares de justicia $<$ término $>$ ), lo que revela que siguen sin resolverse bastantes problemas.

${ }_{21}$ Títulos como Sintassi e intonazione nell'italiano parlato (Voghera 1992), Grammaire de l'intonation (Morel y Danon-Boileau 1998), L'intonation, le système du français (Rossi 1999) -cuyos dos capítulos centrales se titulan «Grammaire de l'intonation pragmatique» $\mathrm{y}$ «Grammaire de l'intonation syntaxique», por ese orden-, Grammaire et prosodie -Collin (dir.) 2008-, Prosodie et sens (Caelen-Haumont 2008), etc., bastan para comprobar que han pasado a ocupar el primer plano. Entre nosotros, aparte de los trabajos mencionados, empieza a destacarse su papel en otros muchos (cf. Montolío 2011).
} 
una grabación de una conversación coloquial (y, con mayor razón, su transcripción) es un material en bruto, de nula o muy débil textualidad, cuyo significado intencional es difícil de desvelar si la mirada (y, sobre todo, el oído) no se desplaza continuamente de las marcas verbales explícitas (incluidos los ordenadores del discurso, a los que tanta atención se viene prestando últimamente) a los recursos para- y extraverbales que explotan los usuarios. Precisamente por eso, y aunque pueda resultar chocante, el necesario acercamiento macrosintáctico se ve facilitado, como diré en seguida, por la utilización de determinadas fuentes escritas.

Ya se sabe que resulta más sencillo señalar insuficiencias que hacer propuestas positivas concretas de aproximación verdaderamente discursiva. Pero para hacer bien esto último, es necesario lo primero. No basta con recurrir a unas cuantas nociones muy amplias, bajo cuyo manto puedan englobarse fenómenos heterogéneos, especialmente aquellos que llaman la atención por su real o aparente singularidad, como, por ejemplo, los procedimientos de realce lingüístico que, según Vigara 2005, «tienen en común el que alteran la estructura de modificación enfática expresiva considerada normal»: algunos adjetivos «irónicos» (¡menudo discursito dio el tío!), a veces «adverbializados» (lo pasé bárbaro); «ciertas partículas (preposiciones, adverbios, conjunciones, artículos) que, precediendo a algún sustantivo, adjetivo, verbo o adverbio, imponen una cierta entonación especial» (Le ha cogido un cariño a Héctor... Qué agradable es...); «términos o expresiones que indican cantidad» (habia una burrada de gente); «modificaciones expresivas en la forma de las palabras» (los árabes, joder, son demasié); "proposición consecutiva» (huele que alimenta, tengo un hambre que me muero); «comparaciones» (es más complicado que la hostia, una gilipollez como la copa de un pino); etc. ${ }^{22}$. Con no basta, entiéndase bien, quiero decir que tal esfuerzo, muy loable, no es suficiente, porque el análisis de tales recursos -muchos de los cuales ni siquiera pertenecen a la construcción libre- no abren la puerta a la sintaxis discursiva. También con la aplicación de supuestos «principios» pretendidamente «explicativos», como el de «comodidad» (Beinhauer habla de economía y comodidad), a lo que la misma autora dedica casi un centenar y medio de páginas, se obvia o se impide cualquier intento serio de explicación macrosintáctica.

\footnotetext{
${ }^{22}$ Bastantes de ellos figuran, junto a otros (prefijos o sufijos, como cuerpazo, superchungo; cuantificadores o sintagmas especificativos con valor semejante: menudo, de cojones; expresiones como para lo que dice, la de veces que se lo he dicho, está que muerde, está como un tren; la realización silabeada, del tipo es un PE-SA-DO) en Briz 1998, al tratar de la «categoría -o función- pragmática» intensificación, «mecanismo argumentativo orientado a regular la conversación». La «intensificación» y la «atenuación» han de verse, según Briz, como dos polos dentro de una misma escala, y son los interlocutores los que eligen el grado y la táctica verbal en virtud de la estrategia maximizadora o minimizadora para lograr la meta prevista.
} 
Como he apuntado, las «anormalidades», anomalías o carencias, que indudablemente se dan (especialmente en hablantes de escasa competencia comunicativa), no deben constituir el principal centro de interés del lingüista, que, además de situarse por encima del listón de lo correcto (las incorrecciones han de corregirse, sin más), siempre ha de intentar trascender la aparentemente abigarrada casuística. Al contrario, para desentrañar la técnica constructiva propia del habla, hay que dejar de contemplar sus usos como meras deficiencias que derivan de la incompetencia, impericia o torpeza, y adoptar un punto de vista que parta del complejo proceso de enunciación y del peculiar modo de producciónrecepción de las actuaciones propias de la inmediatez. Las vacilaciones, interrupciones, estructuras en apariencia truncadas o suspendidas, incompletas o inacabadas, el empleo de expresiones inespecificativas o de muletillas, etc., lejos de responder, sin más, a la incapacidad, desgana o ineptitud, o al ahorro de detalles concretos, derivan de que constantemente en la lengua hablada quedan a la vista (al oído, mejor) «las etapas de su confección», lo que se refleja en la frecuente acumulación de sucesivas elecciones paradigmáticas, en la vuelta atrás sobre una estructura ya iniciada, en la inserción de correcciones o incisos, etc. (BlancheBenveniste 1998). En una cadena de secuencias como

¿Tú te acuerdas del tío que tenía un bar, bueno, un bar, no, un chiringuito, ni siquiera eso, un quiosquillo de mala muerte, en la playa? Pues me lo encuentro el otro día con un Mercedes, no, un BMW, bueno, un cochazo impresionante, y me dice...

es fácil advertir que el hablante va realizando aproximaciones hasta llegar -sin que las anteriores se borren, lo que sí se hace al escribira la que juzga más acorde o cercana a su propósito comunicativo. A ello responde, claro es, el recurso frecuente a marcadores que corrigen, modifican, rectifican..., es decir, reformulan. Que en ese ejemplo la relación primera sea, al menos en la intención, progresivamente reductora (atenuadora) y, en cambio, gradualmente «intensificadora» la segunda, pone de manifiesto lo difícil que es vincular a una «categoría» pragmática en particular procedimientos constructivos propios y específicos $^{23}$. Lo que sí se descubre es que, a diferencia de lo que sucede en otros tipos discursivos, al tratarse de un proceso que se produce en

${ }^{23}$ En este breve diálogo

-Anoche, mi hija, que se tiene que levantar temprano, que la llame a las 6 .

-Pero ¿no tiene despertador?

-¡Tiene DOS despertadores!... y el móvil.

el hablante considera más eficaz la representación dramatizada de la escena que la mera narración distanciadora (Mi hija, pese a tener dos despertadores -además del móvil-, me encargó anoche que la llamara a las 6 , porque tenía que levantarse temprano). 
colaboración y que responde básicamente a razones de eficacia o eficiencia, la selección de los mecanismos idiomáticos está condicionada por la reacción y réplica inmediata de los interlocutores. Nada tiene de extraño que el control predicativo se subordine constantemente al pragmático, o, si se prefiere, que este último permita y favorezca las estructuras «hipoarticuladas» o sintácticamente «débiles». Operar como si fuera al revés es lo que ha llevado a algunos a hablar de la «deformación jerárquica» del lingüista (Simone 1997). Y aunque proyectar en la sintaxis el principio de la relatività della variazione, esto es, no partir necesariamente de la «homogeneidad» de una modalidad de referencia al abordar otra, resulte en la práctica «fortemente antieconomico e in alcuni casi irrealizzabile» (Sornicola 2002, p. 146), son los estudiosos de la lengua coloquial los que están en inmejorables condiciones para adentrarse por todas las sendas -que no son pocas- abiertas por la perspectiva pragmática y para enmendar tal visión desfigurada de la realidad de los muy variados usos idiomáticos. Desde luego, al no poder servirse de ejemplos inauténticos acuñados ad hoc, tienen más fácil la integración del componente pragmático, de lo que, como ya vio hace veinte años G. Rojo, depende el futuro -hoy ya presente- de las investigaciones gramaticales sobre el español ${ }^{24}$.

4. Como no puedo ocuparme de todas las cuestiones pendientes y de los caminos para resolverlas, insistiré, para terminar, en algo a lo que he aludido un par de veces, el trasvase de lo coloquial a la escritura, pues constituye, me parece, el cordón umbilical que puede mantener unida la sintaxis coloquial a la lingüística y a la filología. Ya he dicho que nunca ha sido abandonada -y no debe abandonarse- la vía «indirecta» de indagación que permiten determinados textos, en especial -pero ni mucho menos exclusivamente- ciertas obras literarias en que el autor se propone reflejar la técnica constructiva dominante en las actuaciones interlocutivas propias de la proximidad comunicativa. ¿Por qué la literatura, a la que es posible fingir todas las variedades de uso, ha tardado en acoger plenamente la coloquial? Entre otras razones, porque ello implica una nueva propuesta de lectura, en la que a los lectores corresponde recuperar y actualizar lo que en el intercambio cara a cara se da simul-

\footnotetext{
${ }^{24}$ En el Simposio Internacional de Investigadores de la Lengua Española (SILE), celebrado en Sevilla en 1991, en el que distintos especialistas hicieron balance de las investigaciones sobre la lengua española, G. Rojo, al que se encargó que trazara la situación actual y las perspectivas de los estudios gramaticales de orientación funcionalista aplicados al español, dijo que la marcha de los mismos iba a depender de cómo se fuera resolviendo la «falta de atención a los aspectos pragmáticos», algo a lo que «habrá que poner remedio cuanto antes», añadía. Por razones que no vienen al caso, las Actas del mismo, a pesar de que los organizadores llegamos a corregir las segundas pruebas, nunca llegaron a publicarse, por lo que el texto de G. Rojo apareció en el número 21 de Verba, 1994.
} 
táneamente con lo verbalizado, mucho de lo cual, claro es, no puede ser reflejado por escrito. Al tener no poco de experimento, tal propuesta no está exenta de riesgo, si se llega a tensar en exceso el arco de la capacidad restauradora de unos destinatarios que, no se pierda de vista, reciben el texto como producto cerrado y ajeno. El escritor que decide ponerla en práctica se ve obligado a ejercer un control adicional, para poder llegar a lectores distantes; y cuanto más se ausente, más hará recaer en ellos la reconstrucción, no solo del marco compartido por interlocutores ficticios, sino también de su adecuada contextualización, incluida la prosódica y proxémica. Es precisamente esa ineludible labor manipuladora del autor lo que facilita la labor del lingüista. Ahora bien, este no ha de caer en la trampa que esa engañosa facilidad le tiende, sino que ha de esforzarse en descubrir, además de lo propio o peculiar de la oralidad coloquial que se refleje, cuanto no aflora por haber sido sometido a filtrado, criba o maquillaje.

No puede causar extrañeza que, como acabo de decir, la traslación de la oralidad coloquial a la escritura solo modernamente, y en contadas ocasiones, se haya alcanzado con relativo éxito, y, contra lo que pensaba W. Beinhauer, más en la narrativa que en el teatro, pues las exigencias escénicas y la eficacia dramática requieren la «literaturización», en mayor o menor medida, del texto (Bustos 1996, 1998). Hacer que los personajes de una novela se sirvan de una modalidad de uso más o menos afín a la coloquial, por considerarla apropiada para la creación de mundos imaginados, es decisión que ha de contar con lectores avezados, y habituados, entre otras cosas, a vivificar adecuadamente tal clase de diálogos. No se necesita más que haber dejado de ser analfabeto para entender los achatados de, por ejemplo, cualquier obra de Corín Tellado, de la que suele decirse es la escritora en español más leída, tras Cervantes. Por muy compleja que parezca a veces su sintaxis, no se separa un milímetro de la estándar que, mejor o peor, los gramáticos han venido describiendo desde siempre, como puede comprobarse en este párrafo, extraído de una larguísima intervención en que uno de los personajes de Mi mujer eres tú (1999) se dispone a aclarar, por fin, por qué no es posible el casamiento de dos enamorados:

Sé cómo ama a Andrea, y todos estos días, tanto Ernest como yo, le veníamos pidiendo que te contara todo. Alan se calló, porque tuvo miedo de perder a Andrea. Pero la situación se ha puesto tirante, al rojo vivo, y es preciso que Andrea conozca las causas por las cuales Alan, amándola tanto, no le presentó a su familia, ni le habló de matrimonio, cuando me consta, y ahí está él para desmentirlo si estoy equivocada, el propósito y el anhelo de Alan en casarse con Andrea.

En cambio, no basta saber leer para alcanzar a comprender (desentrañar cabalmente el sentido de un texto es el primer paso para captar 
su valor literario) lo que a través de (mejor, gracias $a$ ) la también aparente sencillez constructiva quiere transmitir C. Martín Gaite en ciertos coloquios de algunas de sus novelas. Así arranca, por ejemplo, el capítulo segundo (sin título) de Irse de casa (1998), que ha de leerse (aunque en la práctica no se haga) en voz alta:

-Ella era muy suya, ¿Qué por qué lo digo?, pues mira, Sole, por todo, desde cómo entraba a los sitios mirando al vacío a cómo rechazaba las invitaciones sin dar las gracias siquiera, que ya acabó por no invitarla nadie a ningún sitio, fíjate, lo hacíamos sobre todo por Olimpia, que la ponía por los cuernos de la luna, con ella sí se juntaba, pero amigas íntimas tampoco, no era de hacerle confidencias a nadie, un ser superior, eso es lo que se creía, total, porque tenía idiomas...

-Cuatro, guapa, cuatro idiomas, y todo a base de becas y de hincar los codos un mes detrás de otro en aquel chiscón con ventanucos de reja que parecía una cárcel, mientras la madre le daba sin tregua a la máquina de coser, yo le veo mucho mérito a estudiar con ese ruido y nunca quejarse.

- ¿Quejarse? Todo lo contrario. Si es lo que yo digo, que se las daba de princesa, ¡unas ínfulas!...

-Y fuerza de voluntad también, como la madre, ¿o no llegó la señora Ramona a vestir a mucha gente principal y a entrar en las mejores casas, viniendo como venía de un pueblo, sin marido y con la niña chica, que no las conocía nadie? Las dos lo mismo, pumba, catapumba, plas, hasta que se situaron.

Cierto, no estamos ante una total novedad. Se han señalado hitos anteriores en la captación del registro coloquial. Seco 1983, que no se olvida del asombroso precedente del Corbacho ${ }^{25}$ (y podría haber añadido otros, como La lozana andaluza), cita a Cervantes (especialmente sus Novelas ejemplares) y la novela realista del XIX, en particular Galdós. Pero de salto cualitativo (no de un simple peldaño más en la tendencia al realismo que se atribuye a nuestra literatura) solo cabe hablar, en mi opinión (Narbona 1992a, 1992b, 1993, 2007a, 2007b), cuando aparecen en la postguerra obras como El Jarama, de R. Sánchez Ferlosio, quien, con todo, sigue ayudándose (y ayudando a los lectores) con abundantes acotaciones que, además de identificar a quien en cada momento corresponde el turno de palabra, proporcionan informaciones acerca del contorno entonativo de sus intervenciones, sus gestos y movimientos, las reacciones que provocan, etc. La determinación de no inmiscuirse en la interlocución de los personajes constituye un paso más, que puede comprobarse en el fragmento aducido de la novela de C. Martín

\footnotetext{
${ }^{25}$ Donde ni siquiera hay diálogo propiamente dicho. Dámaso Alonso habla de simple "plurifurcación», como el rasgo estilístico más sobresaliente del Arcipreste de Talavera (Narbona 1992a).
} 
Gaite, donde se prescinde incluso del verbo dicendi que va señalando los cambios de turno de palabra ${ }^{26}$.

Como he dicho, nada comparable se halla en épocas anteriores, por más que giros y expresiones coloquiales aparezcan en los textos desde la Edad Media. Y la diferencia que hay -me refiero, claro es, solo al grado de acogida de rasgos coloquiales- entre Cervantes y Galdós -casi tres siglos los separan-, con ser notable ${ }^{27}$, es menor que la que se aprecia entre este último y C. Martín Gaite, entre los que apenas transcurre un siglo, o determinados fragmentos de Tiempo de silencio, de Luis Martín Santos, ciertas obras de Fernando Quiñones, como Las mil noches de Hortensia Romero, o de Eduardo Mendicutti, como Ganas de hablar, etcétera.

Que no estoy hablando de una simple vía abierta lo prueba el que contamos ya con destacables logros, como Oralidad y escrituralidad en la recreación literaria del español coloquial, de Araceli López Serena 2007a, o La transcription littéraire de l'oralité en espagnol moderne, Tesis Doctoral recientemente defendida en la Universidad Paris IV-Sorbonne por Sandra Barberie 2009.

Por supuesto, no solo hay que recurrir a la escritura literaria. Un filón inagotable nos ofrece la prensa, en particular la costumbrista y/o

${ }^{26}$ Que el control del autor pase desapercibido al máximo depende de su habilidad a la hora de filtrar lo que de la sintaxis oral debe o no reflejarse por escrito. Muy segura debía de estar C. Martín Gaite de que los lectores de la obra citada no iban a tener dificultad alguna para revivir, por ejemplo, la entonación adecuada, e incluso representarse la gesticulación oportuna, de la intervención final de uno de los cinco jóvenes aspirantes a escritores que discuten sobre si sirve o no para algo asistir a alguna de las escuelas de letras que han empezado a proliferar:

-Yo eso no lo veo una garantía - dijo una chica alta y desgarbada con gafas gruesas-. Ni Flaubert que resucitara podría enseñarte a escribir más que desde lo que él hace, o sea, a copiarle. Y en seguida diría la gente, y con razón, que has plagiado a Flaubert, pues para ese viaje no necesitamos alforjas, tú lees a Flaubert, te sale más barato y lo que se te quede lo asimilas a tu manera. No será un plagio de diseño.

-Pero después te ayudan a colocar el libro y esas cosas.

-Ya, te van a ayudar. Por aquí. Ellos cobran y punto.

Hasta qué punto las lenguas, por muy emparentadas que estén, se apartan bastante menos en esto que en las concretas expresiones verbalizadas, es algo que salta a la vista en su traducción al italiano y al francés:

-Però dopo ti aiutano a piazzare il libro e tutta quella roba li.

-Sì, ti aiutano! Ma va là. Loro intascano i soldi, e basta.

(Via da casa. Trad. M. Finassi. Giunti, Firenze 2000)

-Mais ensuite on t'aide à placer ton livre, e tout le tremblement.

-Ouais, on va t'aider. Tu parles! Aboule le fric, un point et c'est tout.

(Claquer la porte. Trad. C. Bleton. Flammarion, Paris 2000)

${ }_{27}$ No poco se ha escrito del estilo poco artístico -e incluso de la falta de estilo- de Galdós, a quien Valle-Inclán llamó «don Benito el Garbancero». Se insiste en su realismo oral, en el lenguaje corriente e impregnado del tono y las resonancias de la palabra hablada que manifiestan los diálogos de muchos de sus personajes, etc. Aunque tampoco faltan quienes han sabido ver las claves de tal oralidad, muy distante, en todo caso de la de Cervantes (cf. Gilman 1961). 
satírica, en auge desde el siglo XIX. La creciente oralización que hoy se advierte en determinados subgéneros periodísticos, especialmente en el columnismo, que, por sus especiales características (brevedad, asuntos generalmente cotidianos, subjetividad de las opiniones expresadas, etc.), favorece la cercanía con que se intenta atraer a un gran número de lectores, ya ha sido objeto de análisis (Mancera 2009) ${ }^{28}$, si bien la muy distinta situación de lectura explica que la mímesis se reduzca a menudo a una serie de expresiones y recursos constructivos coloquiales que, a modo de pinceladas, se limitan a salpicar, con mayor o menor intensidad, la escritura.

5. De las varias direcciones posibles en que pueden proyectarse y aplicarse los estudios sobre el español coloquial (en campos tan diversos como la traducción e interpretación, los medios audiovisuales de comunicación, incluidas parcelas en auge como el subtitulado de doblaje o para sordos, etc.), en lo que queda tanto por hacer, no diré nada, porque entiendo que caen fuera de los objetivos prioritarios de este Simposio. Tampoco puedo ocuparme del extraordinario apoyo que pueden y deben prestar a la encomiable labor de reforzar y mejorar, por la vía de la enseñanza e instrucción, la competencia idiomática, tanto de los hispanohablantes como de aquellos que no tienen el español como lengua materna y aspiran a dominar, en primera instancia, las modalidades coloquiales. También este camino ha comenzado a ser transitado por el Grupo Val.Es.Co, por ejemplo, con la publicación del libro Saber hablar, coordinado por A. Briz 2008, y concebido, con buen criterio, como «una guía para hablar bien», un «modelo del buen discurso» que ofrece «pautas, consejos y recomendaciones para hablar correctamente, de forma adecuada y de modo eficiente y eficaz» ${ }^{29}$. En efecto, que estemos ante un aprendizaje natural no significa que sea verdad eso de que «a hablar se aprende hablando»; hacerlo correcta, adecuada y eficazmente en cada una de las diversas situaciones comunicativas que se van presentando requiere un aprendizaje y un entrenamiento que nunca pueden darse por acabados. Tampoco es cierto que determinados hablantes no necesiten pasar de la variedad coloquial que sirve para lo inmediato y práctico; nadie se resigna voluntaria y deliberadamente a permanecer anclado en ella, todos aspiran a apoderarse también de aquellas que abren un infinito mundo de posibilidades y tienen unas expectativas que, de no cumplirse, pueden conducir a frustraciones personales y sociales. No es poco lo que se puede hacer para que nadie

\footnotetext{
${ }^{28}$ Cf. también Mancera 2012.

29 Por cierto, de las 270 páginas del libro, salvo ocho dedicadas a la «corrección fónica» y otras tantas a la «corrección léxica», el resto se centra en la sintaxis y organización del discurso.
} 
se deje embaucar por un discurso hueco, para que todos sean capaces de detectar falacias, disparates y plagios, para que cada vez más usuarios puedan despojarse -sobre todo cuando la situación lo requiere o aconseja- de vacilaciones e inseguridades, etc., en suma, para fortalecer el control idiomático incluso de los que, lamentablemente, parecen condenados a hablar de una única y misma forma coloquial. La Tesis Doctoral de Isabel Gómez Díez 2008, dirigida por Teun A. Van Dijk, con el título "Je n'ai que ma bouche»: prácticas interactivas y discursivas en el procedimiento de solicitud de asilo en Bélgica, permite comprobar hasta qué punto unos funcionarios pueden perjudicar a solicitantes de asilo procedentes de países africanos francófonos al hacerles las preguntas y, sobre todo, al poner por escrito sus respuestas coloquiales. Y es que la lingüística, o es sociolingüística o no es nada, o muy poco. También aquí juegan con ventaja los estudiosos de la conversación coloquial.

6. He querido mostrar que los estudios sobre el español coloquial -una vez superada la etapa en que interesaban sobre todo su pintoresquismo ${ }^{30}$ y los fenómenos curiosos- pueden contribuir no poco a evitar o frenar el peligro de que nuestra disciplina caiga en la esterilidad a que puede conducir la inclinación de no servirse más que de un paradigma máximamente formal. A falta de conclusiones, me contentaré con resumir lo que he pretendido decir. Ante todo, que la sintaxis coloquial, pero nunca en solitario, abre un abanico amplio y variado de vías de indagación, que se revelan explicativamente fecundas en parcelas que van desde la historia del español a la lingüística aplicada. En segundo lugar, que la aportación se va plasmando con pasos prudentes, sin saltos en el vacío, lo que no carece de importancia, pues algunas de las innovaciones (o revoluciones) teóricas que se han sucedido durante el siglo pasado ni siquiera han logrado delimitar de forma satisfactoria el objeto, ya que, al aislar un sistema o una competencia (ideal) que resultara abarcable, se han visto abocados a fijarse en enunciados inventados o apartados de su contexto, que son, además, examinados como productos, sin apenas entrar en la complejidad del proceso de producción que subyace a los discursos reales. En nuestro caso, ni cabe análisis des-contextualizado, ni procede explicación alguna que se desentienda de la perspectiva pragmática. Ahora bien, la integración de cuanto había ido quedando fuera de la atención del lingüista no puede hacerse de cualquier forma y a cualquier precio, pues ello implicaría sacrificar los objetivos mismos de la lingüística. Dicho de otro modo, los estudiosos de la sintaxis coloquial son los mejor situados para integrar adecuadamente en la descripción gramatical el componente pragmático, y convertirlo en foco

\footnotetext{
${ }^{30}$ «The term colloquial is commonly felt -albeit often pejoratively- to refer to particular informal (often racy or popular) spoken usage» (Steel 1976, p. 12).
} 
iluminador de los fenómenos lingüísticos. Y por último, que el ensanchamiento de los datos no debe llevarnos a enterrar los hasta ahora utilizados, que pueden y deben seguir explotándose mejor. Así, esa especie de indagación inversa o invertida que busca lo oral en lo escrito (única viable para una gran parte de la historia del español, no se olvide) debe continuar siendo aprovechada, y no solo por lo que puede aportar a la crítica literaria y a los lectores, sino porque lleva a superar los límites y limitaciones de la observación directa de las conversaciones cotidianas. Carece de sentido discutir si una vía es mejor que otra, cuando la confluencia de ambas solo tiene ventajas. Los escritos (incluidos los de ficción) coloquiales no son menos reales, y la criba a que el autor los somete ayuda al lingüista a descubrir recursos que difícilmente puede observar de otro modo.

Tarea, como se ve, no falta, y tampoco parece que falten jóvenes investigadores con ánimo para llevarla a cabo.

\section{REFERENCIAS BIBLIOGRÁFICAS}

(Real) Academia Española y Asociación de Academias de la Lengua Española (2009): Nueva gramática de la lengua española, 2 vols., Madrid, Espasa.

AlbelDA, M. (2007): La intensificación como categoría pragmática: revisión y propuesta, Fráncfort del Meno, Peter Lang.

Alonso, A. (1922): «Español como que y cómo que», RFE 12, pp. 133-156.

Anula, A. (2000): «Los datos y el estudio del lenguaje», en de Miguel, E.; Fernández Lagunilla, M. y Cartoni, F. (eds.), Sobre el lenguaje: miradas plurales y singulares, Madrid, Arrecife, pp. 17-32.

Ávila, A.; Lasarte, M. C. y Villena, J. A. (eds.) (2008): El español hablado en Málaga II. Corpus oral para su estudio sociolingüistico. Nivel de estudios medios, Málaga, Sarriá.

BARBERIE, S. (2009): La transcription littéraire de l'oralité en espagnol moderne, Tesis Doctoral, Université Paris IV-Sorbonne.

BeInHAUer, W. (1968): El español coloquial, 2ª ed., Madrid, Gredos.

BLANCHE-BENVENISTE, Cl. (1998): Estudios lingüísticos sobre la relación entre oralidad y escritura, Barcelona, Gedisa.

- (2005): «De la spécificité de l'oral», en Van Deyck, R.; Sornicola, R. y Kabatek, J. (eds.), La variabilité en langue. Les quatre variations, Gante, Communication \& Cognition, pp. 45-64.

Bosque, I. y Demonte, V. (dirs.) (1999): Gramática descriptiva de la lengua española, 3 vols., Madrid, Espasa.

BRIZ, A. (coord.) y GRUPO VAL.Es.Co (1995): La conversación coloquial (materiales para su estudio), Universidad de Valencia.

- (1996): El español coloquial: situación y uso, Madrid, Arco/Libros.

- (1998): El español coloquial en la conversación. Esbozo de pragmalingüística, Barcelona, Ariel. 
- (coord.) (2008): Saber hablar, Madrid, Instituto Cervantes.

- (2011): «La subordinación sintáctica desde una teoría de las unidades del discurso: el caso de las llamadas causales de la enunciación», en de Bustos, J. J.; Cano, R.; Méndez, E. y López Serena, A. (coords), Sintaxis y análisis del discurso hablado en español. Homenaje a Antonio Narbona, vol. I, Secretariado de Publicaciones de la Universidad de Sevilla, pp. 137-154.

- y Grupo Val.Es.Co (2002): Corpus de conversaciones coloquiales, Madrid, Arco/Libros.

- (2003): «Un sistema de unidades para el estudio del lenguaje coloquial», Oralia 6, pp. 7-61.

Bustos Tovar, J. J. de (1996): «La construcción del diálogo en los entremeses cervantinos», Actas Jornadas XII-XIII, En torno al teatro del Siglo de Oro, Almería, pp. 277-289.

- (1998): «Lengua viva y lenguaje teatral en el siglo Xvi: de los pasos de Lope de Rueda a los entremeses de Cervantes», en Oesterreicher, W.; Stoll, E. y Wesch, A. (eds.), Competencia escrita, tradiciones discursivas y variedades lingüisticas. Aspectos del español europeo y americano en los siglos XVI y XVII, Tubinga, Gunter Narr, pp. 421-444.

Cabedo Nebot, A. (2009): La segmentación prosódica en español coloquial, Universidad de Valencia.

- y López Navarro, E. (2012): «Duración de unidades discursivas como posible marca distintiva de los hablantes», Comunicación presentada en el XLI Simposio de la SEL, Valencia 2012.

Caelen-Haumont, G. (2008): Prosodie et sens. Un approche expérimentale, París, L'Harmathan.

Collin, C. (dir.) (2008): Grammaire et prosodie, Presses Universitaires de Rennes.

Company, C. (2006): «Gramaticalización y frecuencia de uso. Los paradójicos sintagmas con artículo + posesivo del español medieval», RHLE 1, pp. 6-30.

- (2008): «Gramaticalización, género discursivo y otras variables en la difusión del cambio sintáctico», en Kabatek, J. (ed.), Sintaxis histórica del español y cambio lingüístico: Nuevas perspectivas, Madrid-Fráncfort del Meno, Vervuert, pp. 17-51.

Cortés Parazuelos, $M^{\underline{a}}$ H. (1994): «La oración conclusiva con el molde es... y..., conque...», RSEL 24/2, pp. 345-378.

Cortés Rodríguez, L. (2002a): Los estudios del español hablado entre 1950 y 1999, Madrid, Arco/Libros.

- (2002b): «Español coloquial: concepto y status quaestionis», EA 77-78, pp. 27-41.

- y Самасно, M. M. (2005): Unidades de segmentación y marcadores del discurso, Madrid, Arco/Libros.

CRIAdo De VAL, M. (1959): Gramática española y comentario de textos, Madrid, $\mathrm{S} \cdot \mathrm{A} \cdot \mathrm{E} \cdot \mathrm{T} \cdot \mathrm{A}$.

ELVIRA, J. (2005): «Los caracteres de la lengua en el siglo XIII: gramática de los paradigmas y de la construcción sintáctica del discurso», en Cano, R. (coord.), Historia de la lengua española, Barcelona, Ariel, pp. 449-472.

FAARLUND, J. T. (1990): Syntactic change: Towards a theory of historical syntax, Berlín-Nueva York, Mouton de Gruyter.

FreI, H. (1929): La grammaire des fautes, Génova, Slatkine Reprints. 
Fuentes, C. (2000): «La ambigüedad del término secuencia en el análisis del discurso", Actas IV Congreso de lingüistica general 3, pp. 1129-1141.

GARACHANA, M. (2008): «En los límites de la gramaticalización. La evolución de encima (de que) como marcador del discurso», RFE 88, pp. 7-36.

Gaviño, V. (2008): Español coloquial. Pragmática de lo cotidiano, Servicio de Publicaciones de la Universidad de Cádiz.

GILMAN, S. (1961): «La palabra hablada y Fortunata y Jacinta», NRFH 15, pp. $542-$ 560.

GIRÓN, J. L. (2003a): «Evolución de la cohesión en el discurso ensayístico entre 1648 y 1726», Estudios ofrecidos al profesor J. Jesús de Bustos Tovar, Vol. I, Madrid, Editorial Complutense, pp. 331-360.

- (2003b): «Gramática y discurso en la época de Calderón», en Lara, J. (ed.), El mundo como teatro. Estudios sobre Calderón de la Barca, Málaga, Universidad de Málaga, pp. 151-174.

- (2004): «Gramaticalización de los marcadores del discurso e historia de conque», Lexis 28, Homenaje a J. L. Rivarola, vol. II, pp. 157- 198.

- (2009): «Las oraciones de relativo II. Evolución del relativo compuesto el que, la que, lo que», en Company, C. (dir.), Sintaxis histórica de la lengua espanola. Segunda parte: La frase nominal, vol. II, pp. 1477-1590.

- (2012): «Los relativos compuestos españoles y su interés para la teoría de la gramaticalización», VIII Congreso internacional de historia de la lengua espanola, Santiago de Compostela, Meubook, pp. 57-75.

Gómez DíEz, I. (2008): «Je n'ai que ma bouche»: prácticas interactivas y discursivas en el procedimiento de solicitud de asilo en Bélgica, Tesis Doctoral, Universidad Pompeu Fabra de Barcelona.

Gómez Molina, J. R. (ed.) (2001-2007): El español hablado en Valencia. Materiales para su estudio. I: Nivel sociocultural alto. II: Nivel sociocultural medio. III: Nivel sociocultural bajo, Universidad de Valencia.

González Ollé, F. (1982): Textos para el estudio del español coloquial, 3ª ed., Pamplona, EUNSA.

Heine, B. y Kuteva, T. (2002): World lexicon of grammaticalization, Cambridge, Cambridge University Press.

HidAlGO, A. (2003): «Microestructura discursiva y segmentación informativa en la conversación coloquial», ELUA 17, pp. 367-385.

- (2004): «Las unidades de la conversación: acto y subacto como segmentos menores del análisis», en Cano López, P. (ed.), Actas VI Congreso de lingüística general, Universidad de Santiago de Compostela, pp. 3365-3380.

- (2011): «Segmentación y discurso oral: notas sobre el papel demarcativo de la prosodia en la conversación», en de Bustos, J. J.; Cano, R.; Méndez, E. y López Serena, A. (coords): Sintaxis y análisis del discurso hablado en español. Homenaje a Antonio Narbona, vol. I, Secretariado de Publicaciones de la Universidad de Sevilla, pp. 237-258.

— ; Congosto, Y. y Quilis, M. (eds.) (2011): El estudio de la prosodia en España en el siglo XXI: perspectivas y ámbitos, Universitat de Valéncia.

IgLesias, S. (2000a): «Oralidad y escritura en la Edad Media: observaciones sobre la historia de $c a$ y que», Oralia 3, pp. 277-296.

- (2000b): «La evolución histórica de pues como marcador discursivo hasta el siglo XV», BRAE 80, pp. 209-307. 
Julián, O. (2010): «A menos que Galdós opine lo contrario ... Locuciones condicionales exceptivas en la obra galdosiana», en J. Sueiro et alii (eds.), Lingüistica e Hispanismo, Lugo, Axar, pp. 311-323.

Kаватек, J. (ed.) (2008): Sintaxis histórica del español y cambio lingüistico: Nuevas perspectivas desde las Tradiciones Discursivas, Madrid-Fráncfort del Meno, Iberoamericana-Vervuert.

KOCH, P. y OESTERREICHER, W. (2000): «Langage parlé et langage écrit», en Holtus, G.; Metzeltin, M. y Schmitt, Chr. (eds.): Lexikon der Romanistischen Linguistik, Band 1, Tubinga, Niemeyer.

LAPESA, R. (1966): «El, la, lo como antecedente de relativo en español», Estudios de filología e historia literaria lusohispanas e iberoamericanas publicados para celebrar el tercer lustro del Instituto de Estudios hispánicos, portugueses e iberoamericanos de la Universidad estatal de Utrecht, La Haya, pp. 287-298. Recogido en Lapesa 2000, vol. I, pp. 389-401.

- (1968): «Evolución sintáctica y forma lingüística interior en español», Actas del XI CILFR, pp. 131-150. Recogido en Lapesa 2000, vol. I, pp. 32-53.

- (1970): «Sobre problemas y métodos de una sintaxis histórica», Homenaje a Xavier Zubiri, vol. II, pp. 199-213, recogido en Lapesa 2000, vol. I, pp. 54-69.

- (1978): «Sobre dos tipos de subordinación causal», en Estudios ofrecidos a E. Alarcos, vol. III, Oviedo, pp. 173-205. Recogido en Lapesa 2000, vol. II, pp. 896-927.

- (2000): Estudios de morfosintaxis histórica del español, edición de Cano, R. y Echenique, T. M. ${ }^{-}, 2$ vols., Madrid, Gredos.

Lasarte, M. C.; Sánchez, J. M.; Ávila, A. y Villlena, J. A. (eds.) (2009): El español hablado en Málaga III: Corpus oral para su estudio sociolingüístico. Nivel de estudios superior, Málaga, Sarriá.

LÓPEZ SERENA, A. (2007a): Oralidad y escrituralidad en la recreación literaria del español coloquial, Madrid, Gredos.

- (2007b): «El concepto de español coloquial: vacilación terminológica e indefinición del objeto de estudio», Oralia, 10, pp. 161-191.

MANCERA, A. (2009): Oralización de la prensa española: la columna periodística, Tubinga, Peter Lang.

- (2012): «Muestras de sintaxis oralizada en los diarios decimonónicos españoles», VIII Congreso internacional de historia de la lengua española, Santiago de Compostela, Meubook, II, pp. 2277-2287.

Marchello-Nizia, Ch. (2006): Grammaticalisation et changement linguistique, Bruselas, De Boeck.

MonTolío, E. (2011): «Gramática y conversación: oraciones compuestas construidas en el diálogo», en de Bustos, J. J.; Cano, R.; Méndez, E. y López Serena, A. (Coords.), Sintaxis y análisis del discurso hablado en español. Homenaje a Antonio Narbona, vol. I, Secretariado de Publicaciones de la Universidad de Sevilla, pp. 313-324.

Morel, M.-A. y Danon-Boileau, L. (1998): Grammaire de l'intonation. L'exemple du français, París, Ophrys.

Moreno, F.; Cestero, A. M.; Molina, I. y Paredes, F. (2002-2007): La lengua hablada en Alcalá de Henares. Corpus PRESEEA-Alcalá. I: Hablantes de instrucción superior. II: Hablantes de instrucción media. III: Hablantes de instrucción primaria, Universidad de Alcalá. 
Moya, J. A. (ed.) (2007): El español hablado en Granada. Corpus oral para su estudio sociolingüístico. I: Nivel de estudios alto, Universidad de Granada.

- (coord.) (2008): El español hablado en Granada. Corpus oral para su estudio sociolingüistico. II: Nivel de estudios medio, Universidad de Granada.

NARBOnA, A. (1986): «Problemas de sintaxis coloquial andaluza», RSEL 16/2, pp. 229-275, Recogido en Narbona 1989, pp. 171-203.

- (1989): Sintaxis española: nuevos y viejos enfoques, Barcelona, Ariel.

- (1992a): «Notas sobre sintaxis coloquial y realismo en la literatura narrativa española», en Bartol, J. A. et al. (eds.), Estudios Filológicos en Homenaje a E. de Bustos Tovar, vol. II, Universidad de Salamanca, pp. 667-673.

- (1992b): «La andadura sintáctica coloquial en El Jarama», en Ariza, M. (ed.), Problemas y métodos en el análisis de textos. In memoriam A. Aranda, Universidad de Sevilla, pp. 227-260.

- (1996a): «Construcciones ¿absolutas? de participio», Actas del III Congreso internacional de historia de la lengua española (Salamanca, 22-27 de noviembre de 1993), vol. I, Madrid, Arco/Libros, pp. 457-469.

- (1996b): «Como que y cómo que, setenta años después», Lexis 20 (Centenario de A. Alonso: 1896-1996), pp. 509-523.

- (1997a): «Breve panorama de los estudios de sintaxis del español coloquial en España», en Calvi, M. V. (dir.), La lingua spagnola dalla transizione a oggi (1975-1995), Viareggio, Lucca, pp. 91-104.

- (1997b): «Sintaxis del español coloquial: algunas cuestiones previas», en Briz, A. et al. (eds.), Pragmática y gramática del español hablado. Actas del II Simposio sobre análisis del discurso oral, Valencia, Universidad de ValenciaPórtico, pp. 157-175.

- (2000): «Sintaxis histórica y sintaxis descriptiva: interrelación y limitaciones», Homenaje a V. Lamiquiz, Madrid, Arco/Libros, pp. 665-681.

- (2003a): «Oralidad: los datos y las gramáticas», en Bustos, J. J. (ed.), Actas del Seminario: «Textualización y oralidad», Madrid, Instituto Universitario Menéndez Pidal, pp. 13-25.

- (2003b): «Variación y sintaxis», Lengua, variación y contexto. Estudios dedicados a H. López Morales, Madrid, Arco/Libros, pp. 763-774.

- (2004): «Cambios y tendencias gramaticales en el español moderno», en Cano, R. (coord.), Historia de la lengua española, Barcelona, Ariel, pp. 10111035.

- (2007a): «Cuando lo coloquial se convierte en literario», en Delgado, I. y Puigvert, A. (eds.), Ex admiratione et amicitia. Homenaje a R. Santiago, vol. II, Madrid, Ediciones del Orto, pp. 849-858.

- (2007b): «Sintaxis de la escritura de lo oral en los diálogos del Quijote», en Cortés, L. y otros (coords.), Discurso y oralidad. Homenaje al profesor José Jesús de Bustos Tovar, vol. I, Madrid, Arco/Libros, pp. 65-111.

- (2008a): «La problemática descripción del español coloquial», en Stark, E.; Schmidt-Riese, R. y Stoll, E. (eds.), Romanische Syntax im Wandel, Tubinga, Gunter Narr, pp. 549-565.

- (2008b): «Qué comparar en sintaxis histórica de la lengua española», en Company, C. y Moreno de Alba, J. (eds.), Actas VII CIHLE, vol. II, Madrid, Arco/Libros, pp. 2255-2271. 
- (2009a): «Lapesa y los estudios sobre subordinación oracional del español», en Bustos, J. J. y Cano, R. (eds.), La obra de Lapesa desde la filología actual, Madrid, Sociedad Estatal de Conmemoraciones Culturales, pp. 197-212.

- (2009b): «La felicidad es algo que pueda compartirse. Nota (sin notas) sobre un empleo del subjuntivo», en Veyrat, M. y Serra, E. (eds.), La lingüística como reto epistemológico y como acción social. Estudios dedicados al profesor Ángel López García con ocasión de su sexagésimo aniversario, vol. I, Madrid, Arco/Libros, pp. 489-500.

- (2012): «Fuentes escritas para el estudio de la oralidad», en F. Montero (ed.), Actas VIII Congreso internacional de historia de la lengua española, Universidad de Santiago de Compostela, vol. I, pp. 343-356.

- (en prensa): «Cuando es el otro el que subordina», La subordination à travers les langues romanes. Hommage au Professeur Henry-José Deulofeu, Université de Provence.

Oesterreicher, W. (1994): «El español en textos escritos por semicultos. Competencia escrita de impronta oral en la historiografía indiana», en Lüdtke, J. (comp.), El español de América en el siglo XVI, Actas del Simposio del Instituto Ibero-Americano, Berlín, 23-24 abril 1992, Universidad de Valladolid, pp. 155190.

- (1996): «Lo hablado en lo escrito. Reflexiones metodológicas y aproximación a una tipología», Actas del coloquio internacional El español hablado y la cultura oral en España e Hispanoamérica, Berlín, 23-25 de septiembre 1993, Fráncfort del Meno-Madrid, pp. 317-340.

- (2005): «Textos entre inmediatez y distancia comunicativas. El problema de lo hablado escrito en el Siglo de Oro», en Cano, R. (coord.), Historia de la lengua española, Barcelona, Ariel, pp. 729-769.

PONS BORDERÍA, S. (2008): «Gramaticalización por tradiciones discursivas: el caso de esto es», en Kabatek, J. (ed.), Sintaxis histórica del español y cambio lingüístico: Nuevas perspectivas, Madrid-Fráncfort del Meno, Vervuert, pp. 249-274.

Pons RodRíGUEZ, L. (2007): «La qual çibdad: las relativas con antecedente adjunto del siglo XIII a hoy. Evolución de un procedimiento cohesivo", Romanistisches Jahrbuch 58, pp. 275-305.

Rojo, G. (1994): «Estado actual y perspectivas de los estudios gramaticales de orientación funcionalista aplicados al español», Verba 21, pp. 7-23.

Rossi, M. (1999): Lintonation, le système du français: description et modélisation, París, Ophrys.

SAussure, F. de (1985): Cours de linguistique générale (edición de Tulio di Mauro), París, Payot.

Schwenter, S. A. y Pons Bordería, S. (2005): «Por poco (no): explicación sincrónica y diacrónica de sus componentes de significado», LEA 27/1, pp. 131-156.

SEco, M. (1983): «Lengua coloquial y literatura», Boletín Informativo de la Fundación Juan March 129, pp. 3-22.

SEnABre, R. (1992): «Lengua coloquial y lengua literaria», Boletín Informativo de la Fundación Juan March 221, pp. 3-14.

Simone, R. (1997): «¿Cuál es la lengua de default en un ambiente de variación?», en Narbona, A. y Ropero, M. (eds.), El habla andaluza. Actas del Congreso del habla andaluza, Sevilla, SPHA, pp. 29-41. 
SoRnicola, R. (2002): «La variazione dialettale nell'area costiera napolitana. Il progetto di un Archivio di testi dialettali parlati», Bolletino Lingüistico Campano 1, pp. 131-155.

SPITZER, L. (2007): Lingua italiana del dialogo, edición de Claudia Caffi y Cesare Segre, Milán, il Saggiatore.

Vida CASTRo, M. (ed.) (2007): El español hablado en Málaga. Corpus oral para su estudio sociolingüistico, I. Nivel de estudios bajo, Málaga, Sarriá.

Vigara, A. M. ${ }^{\text {a }}$ (2002): «Estudio del español coloquial: razones para el optimismo», Español actual. Revista de español vivo 77-78, pp. 5-26.

- (2005): Morfosintaxis del español coloquial. Esbozo estilístico, 2a ed., Madrid, Gredos.

Voghera, M. (1992): Sintassi e intonazione nell'italiano parlato, vol. II, Bolonia, Mulino.

Willems, D. (1998): «Donées et théories en linguistique: Réflexions sur une relation tumultueuse et changeante», en Bilger, M.; van den Eynde, K. y Gadet, F. (eds.), Analyse linguistique et approches de l'oral recueil d'études offerts en hommage à Cl. Blanche-Benveniste, Lovaina-París, Peeters, pp. 79-87. 
(01)-Art. Narbona. RSEL 42-2:(7)-Revista Ac. no \&4) 14/1/13 12:21 Página 32 